\title{
DE INVLOED VAN DE OPPERSTE LEIDING OP DE GANG VAN ZAKEN IN HET BEDRIJF
}

\author{
door S. C. Bakkenist, ec. drs.
}

Het ene bedrijf gaat goed; behaalt jaar in, jaar uit een bevredigende rentabiliteit; slaagt erin zijn marktaandeel gestadig uit te breiden. Kort gezegd, vertoont een gezonde ontwikkeling. Het andere bedrijf kampt voortdurend met moeilijkheden; maakt verlies; kan het kwaliteitsniveau van zijn produkten niet op peil houden; worstelt met personeelsproblemen; ziet zijn marktaandeel teruglopen. Zowel in het ene als in het andere geval dringt zich keer op keer de vraag op: aan welke oorzaken kan in het ene geval de goede gang van zaken en in het andere geval de teleurstellende gang van zaken worden toegeschreven. Spreekt men met de directie van het minder succesvolle bedrijf, dan zijn de argumenten meestal: de hevige concurrentie welke van de grotere collega's wordt ondervonden; een minder goede conjunctuur; structurele veranderingen in de bedrijfstak; smaakverschuivingen bij de afnemers; gebrek aan medewerking van de wederverkopers, zoals groothandel en kleinhandel; personeelsproblemen tengevolge van een krappe arbeidsmarkt. Het succesvolle bedrijf verkeert evenwel in soortgelijke omstandigheden, zodat hierin de verklaring niet kan zijn gelegen. Langs deze weg is het dan ook niet mogelijk een min of meer algemeen antwoord te vinden op de hiervoor gestelde vraag. Het is een fascinerende vraag. Is het mogelijk hierop door voortgezette waarneming en nauwkeurige analyse van het bedrijfsgebeuren een antwoord te geven? Ik meen deze vraag bevestigend te kunnen beantwoorden. Ja, het is mogelijk. Ik stel het antwoord waartoe ik gekomen ben voorop, t.w.:

De bekwaamheid, waarmede de opperste leiding zich van haar taak $k w i j t$ is van beslissende betekenis voor het doeltreffend functioneren van een organisatie 1 ).

Ik realiseer mij zeer wel, dat dit antwoord toelichting behoeft en het ver band tussen ,bekwame leiding" en "goed functioneren" aannemelijk zal moeten worden gemaakt, met name in het grootbedrijf. Daarbij zal het de lezer in het bijzonder interesseren hoe die invloed van de opperste leiding op de gang van zaken, met name in het grootbedrijf, zich effectueert. Opnieuw wil ik het antwoord voorop stellen:

De opperste leiding oefent middels de succesvolle keuze van zijn medewerkers, die op sleutelposities zijn geplaatst, alsmede door de regelmatige indoctrinatie van deze medewerkers met zijn visie een beslissende invloed uit.

Vervolgens meen ik, dat het verschijnsel, dat wij ongetwijfeld allen uit eigen ervaring kennen, t.w. dat de goede gang van zaken in een bepaald bedrijf bij wisseling van personen aan de top in betrekkelijk korte tijd in een slechte gang van zaken kan omslaan, zijn verklaring moet vinden in het gebrek aan bekwaamheid van de nieuw benoemde topfunctionaris en zijn verstorende invloed op de staf van naaste medewerkers.

Omgekeerd zal het vervangen van een minder bekwaam directeur door een bekwaam directeur reeds spoedig zijn gunstige invloed uitoefenen door het vervangen van minder bekwame medewerkers door wel voor hun taak

1) Let wel: ik spreek van organisatie, omdat ik van oordeel ben, dat deze stelling voor alle organisaties, dus niet alleen voor bedrijfshuishoudingen, geldend is. 
berekende personen. Tenslotte komt leiding geven neer op: Kiezen van mensen welke tot een prestatie in team-verband moeten worden gestimuleerd.

Thans de nadere analyse en motivering van het hiervoor gestelde. Zoals gezegd: de bekwaamheid waarmede de opperste leiding zich van haar taak kwijt, is van beslissende betekenis voor het doeltreffend functioneren van een organisatie. Dientengevolge is het begrijpelijk dat top-management de laatste jaren in toenemende mate in het middelpunt van de belangstelling staat. Toch wordt de stelling, waarmede deze beschouwing is aangevangen, nog allerminst algemeen aanvaard. Het is zeer goed te begrijpen dat zij velen maar moeilijk aanspreekt, vooral wanneer het gaat om grote organisaties. In kleine bedrijven is het contact van de directeur met de uitvoerders van de werkzaamheden waaraan hij leiding moet geven, nog gemakkelijk en frequent. Door persoonlijke waarneming kan hij zich regelmatig op de hoogte stellen van de wijze, waarop de uitvoering plaats vindt. Hij kan $z$ ich regelmatig, veelal tot in details, overtuigen dat overeenkomstig zijn inzichten en instructies wordt gehandeld en in geval van afwijkingen, kan hij snel corrigerend optreden. Dat in deze gevallen de geponeerde stelling houdbaar is, zal weinig discussie ontmoeten. Anders wordt het echter, wanneer de bedrijfsomvang toeneemt. Wanneer er niveau's komen tussen de opperste leiding en de uitvoering. Het regelmatig contact tussen directie en uitvoering is verbroken. De directie kan zich niet meer door persoonlijke waarneming overtuigen, dat alles in overeenstemming met haar inzichten geschiedt. Evenmin kan de directie rechtstreeks door persoonlijke instructies op de uitvoering invloed uitoefenen. Zoals gezegd, er komen niveau's tussen directie en uitvoering. Eerst boven de uitvoerders, de bazen, daarboven de afdelingchefs en daarboven groepschefs of bedrijfsleiders of onderdirecteuren of mede-directeuren, voorzover het om een organisatie gaat die volgens de beginselen van de lijnorganisatie is opgebouwd. Maar veelal zal men in de grotere bedrijven een lijn/staf/organisatie aantreffen, dat wil zeggen dat er ook nog staffunctionarissen bijkomen, die de leiding op de verschillende niveau's ten behoeve van hun leidinggevende taak bijstaan.

Het aantal uren dat een directie 2) voor haar leidinggevende taak beschikbaar heeft is gering, bijzonder gering als dit aantal uren gesteld wordt tegenover het aantal uren dat in totaal aan het leiding geven door de leidinggevende functionarissen tezamen wordt besteed. Deze uren-schaarste noopt de directie voortdurend taken en beslissingen af te stoten naar beneden. Het is duidelijk dat de directie hierbij bijzonder zorgvuldig te werk moet gaan. Beslissingen die voor het bedrijf van levensbelang zijn moet de directie aan zich houden, maar aangeven welke concrete zaken wel voor delegatie in aanmerking komen en welke niet, is bijzonder moeilijk. Trouwens, de overbelasting waarmede vele directies voortdurend worstelen, brengt met zich dat bij het rangschikken van de zaken die wel en die niet op de directietafel moeten verschijnen, in het geheel niet zorgvuldig te werk wordt gegaan. De zogenaamde historisch gegroeide verhoudingen, de persoonlijke belangstelling en deskundigheid van de directie, oefenen een beslissende invloed uit. Nog veel te weinig is de inhoud van de directiezaak voorwerp van een systematische, zakelijke analyse die zonder aanzien des persoons wordt uitgevoerd. En toch is het dwingend noodzakelijk, wanneer het algemene verschijnsel van de overbelasting en het daarmede samenhangende ziekteverschijnsel, de z.g. managerziekte, met succes wil worden bestreden.

2) Ik spreek op dit moment opzettelijk van directie en laat hiermede in het midden, of er sprake is van één directeur of van een college van twee of meer directeuren. Hierop kom ik in het vervolg van mijn betoog nog terug. 
Behalve het afstoten van beslissingsbevoegdheid naar beneden is de zeer voor de hand liggende oplossing voor de overbelasting, de uitbreiding van het aantal directieleden. Naar mate het bedrijf in omvang groeit kan ook de directie-bezetting groeien. De directie groeit uit één directeur tot een college van directeuren. Er komt een taakverdeling en oppervlakkig beschouwd schijnt het vraagstuk van de overbelasting oplosbaar door uitbreiding van het aantal directeuren dat de opperste leiding van een groot bedrijf verzorgt. Opzettelijk schrijf ik: ,schijnt" het vraagstuk te zijn opgelost. Want met de groei van het aantal directeuren en de hieruit voortspruitende taakverdeling, dient $z$ ich het vraagstuk van de coördinatie van de directie-arbeid aan. En deze coördinatie is werkelijk geen eenvoudige opgave. Dit zullen allen toestemmen, die òf van een college van directeuren deel uitmaken, òf in de gelegenheid zijn een kijkje te nemen achter de deuren van de directiekamers bij de bedrijven, waar een college van directeuren werkzaam is. Maar niet alleen doeltreffende taakverdeling en coördinatie vragen om aandacht. Daarnaast mag niet uit het oog worden verloren, dat ook al verzorgt in het grootbedrijf een college van directeuren de opperste leiding, het totaal aantal uren dat zij gezamenlijk ter beschikking hebben voor hun leidinggevende taak, beangstigend gering blijft ten opzichte van het geheel. Ook voor het college van directeuren in het grootbedrijf blijft de vraag zich opdringen, hoe het mogelijk is dat de directie een beslissende invloed op de gang van zaken kan uitoefenen.

Limperg heeft in zijn colleges aandacht aan het vraagstuk van de opperste leiding geschonken. Hij heeft zich zonder voorbehoud voorstander van de éénhoofdige leiding verklaard ${ }^{3}$ ). Alleen de éénhoofdige leiding is naar zijn oordeel in staat op bevredigende wijze, ook in het grootbedrijf, de leidinggevende taak op het hoogste niveau te verzorgen. Want, zo betoogt limperg, het collegiale bestuur leidt of tot het ophouden van beslissingen, of tot het nemen van beslissingen, die een compromis zijn tussen de verscheidenheid van meningen die over levensvragen voor het bedrijf in de directie bestaan. Ja, maar zo hebben velen tegengeworpen: zie om $U$ heen, en zie hoe vele bedrijven met succes door een college van directeuren worden bestuurd. Hoe is dan de stelling te verdedigen, dat de éénhoofdige leiding verre de voorkeur moet verdienen? Limperg heeft steeds geantwoord: in vele gevallen heeft één van de directie-leden statutair een beslissende stem, hetzij als voorzitter van het college van directeuren, hetzij omdat hij als president-directeur of hoofddirecteur uitdrukkelijk boven de andere directeuren is geplaatst. In een aantal gevallen mag formeel de bovenbeschikking van één van de directeuren niet hebben plaats gevonden; maar dan is deze in feite toch, door de kracht van zijn persoonlijkheid of zijn superieure deskundigheid, aanwezig. Deze directeur is duidelijk de leider van het directie-college. Hij wordt als zodanig door de anderen aanvaard, en als zodanig ook door het bedrijf en de buitenwereld erkend. Het aantal gevallen waar de éénhoofdige leiding daadwerkelijk bestaat, is dan ook veel groter dan men bij oppervlakkige waarneming zou menen.

Persoonlijk deel ik de zienswijze van Limperg op dit punt volledig. Dit beginsel heeft mij van de aanvang af aangesproken, en de ervaring die ik sinds het verlaten van de college-banken in de praktijk heb opgedaan, heeft mij steeds meer van de juistheid van deze, voor een doeltreffende organisatie van de opperste leiding, zo belangrijke richtlijn overtuigd. Daarbij heeft het mij herhaaldelijk getroffen dat degenen, die zich tot voorstander van

3) Zie dictaat-Ribbius: Leer der Organisatie, deel IV.

$\mathrm{m} \mathrm{a} \mathrm{b}$ blz. 466 
het collegiaal bestuur verklaren voor de organisatie van de opperste leiding, voor de niveau's daaronder wel het beginsel van de éénhoofdige leiding aanvaarden en in toepassing brengen.

Ik realiseer mij ten volle, dat er nog heel wat te zeggen is over het beginsel van de éénhoofdige leiding. I $k$ wil dit niet doen en ermede volstaan verband te leggen tussen dit beginsel en de stelling, waarmede ik deze beschouwingen ben aangevangen. Deze zal dan moeten luiden, dat de bekwaamheid waarmede de directeur of, in het college van directeuren, de leider van het college, zich van zijn taak kwijt van beslissende betekenis is. Uiteindelijk is dus het wel en wee, ook in het grootbedrijf, van één man afhankelijk. Ongetwijfeld een gewaagde conclusie. Ik meen dat het empirisch onderzoek voldoende materiaal voor de juistheid kan verschaffen. Maar dit op zichzelf is niet voldoende. De vraag blijft zich dan nog opdringen: hoe is dat mogelijk; hoe kunnen de invloeden, de inzichten van deze ene man aan de top zodanig in de grote organisatie doorwerken, dat zij op de duur van beslissende invloed blijken te zijn? Met de beantwoording van deze vraag zal ik mij in het hiernavolgende bezig houden. Hiertoe is het nodig de taak van de hoofddirecteur nader te analyseren. Daaruit kan blijken, waarop het in het bijzonder bij de leidinggevende taak op het hoogste niveau aankomt. Hieruit kan dan de verklaring voor dit ,wonder", want dat is het eigenlijk in het grootbedrijf, voortspruiten.

Limperg heeft de leidinggevende taak onderscheiden in: dirigerende en constituerende leiding ${ }^{4}$ ). Naar mijn oordeel een waardevolle onderscheiding ten behoeve van de analyse van de taak van de opperste leiding. Onder dirigerende leiding is dan te verstaan, het leiding geven aan de dagelijkse bedrijfsvoering. Onder constituerende leiding, het geven van aanwijzingen en het nemen van beslissingen, die van constituerende aard zijn, dat wil zeggen van vormende aard voor de structuur van de organisatie, voor de filosofie van het bedrijf en voor de expansie. Het wil mij voorkomen dat naast deze onderscheiding in tweeën er plaats is voor een andere onderscheiding in tweeën, die zich niet richt naar de aard van de beslissingen, maar naar het object waarover beslist moet worden. De opperste leiding moet zich niet alleen bezig houden met de dagelijkse problemen die zich voortdurend aandienen en om oplossing vragen, maar moet zich ook en vooral bezig houden met de problemen van de toekomst. Besturen is vooruitzien, is een veel gebruikte uitdrukking; alleen wordt er zo weinig naar gehandeld. In vele bedrijven is de directie zodanig belast met het afhandelen van de vraagstukken van vandaag, dat of in het geheel geen tijd of onvoldoende aandacht aan de vraagstukken over één jaar, over vijf jaar, over tien jaar wordt geschonken. En vooral in het grootbedrijf is dit voor het handhaven van de relatieve plaats in de bedrijfstak van de grootste betekenis. Het verzekeren van continuiteit in de winstgevendheid wordt terecht als één van de hoofdtaken van de opperste leiding beschouwd. Juist het verzekeren van deze continuiteit in de winstgevendheid vereist aandacht voor de toekomstvragen. Vernieuwing van het assortiment, het veroveren van nieuwe afzetgebieden, het tijdig treffen van maatregelen opdat functionarissen, die sleutelposities in het bedrijf bezetten, kunnen worden opgevolgd indien zij promotie maken of het bedrijf verlaten. De toekomstvisie is voor het voortbestaan wel zeer belangrijk.

Ten behoeve van een juist inzicht in de inhoud van de taak van de opper-

4) Zie dictaat-Ribbius: Leer der Organisatie deel IV.

$\mathrm{m} \mathrm{a} \mathrm{b}$ blz. 467 
ste leiding wil ik tenslotte nog wijzen op de omschrijving, die Lievegoed geeft 5 ). Hij zegt:

„Het top-management tenslotte zal hoofdzakelijk conceptuele vaardigheden moeten kunnen ontwikkelen. Hier vindt de beleidsbepaling plaats, het constituerend leiderschap berust voor een zeer groot deel op de conceptuele vaardigheden van de hoogste leiding.

Conceptuele vaardigheden bestaan uit het vermogen in de toekomst bepaalde dingen te kunnen zien aankomen, deze op de juiste wijze in het heden te interpreteren en deze te verbinden met de historische kennis, die men heeft om zodoende te komen tot het vormen van beleidslijnen."

Uit de literatuur over top-management kan een samenvattend oordeel over de inhoud van de taak van de topleiding worden afgeleid. Want de één heeft de aandacht gevestigd op de betekenis van ,"policy-making", de ander op de noodzaak een omlijning te geven van de ",philosophy" van het bedrijf. Weer een ander heeft de behoefte aan de z.g. ,company-planning", dat wil zeggen het ontwerpen van een schets, hoe het bedrijf er over bijvoor beeld 10 jaar zal uitzien, beklemtoond. Allemaal aspecten van constituerende leiding, van op de toekomst gerichte leiding. En hiermede is naar mijn oordeel duidelijk de hoofdtaak van de directeur of de leider van het college van directeuren geschetst. Het is zijn taak de lijnen te trekken, die de richting markeren waarin het bedrijf zich in de komende jaren zal ontwikkelen. Het is deze toekomst-visie, die voor de winst-continuiteit beslissend is. Het zal ook duidelijk zijn, dat op deze levensvragen niet met een compromis mag worden geantwoord. De opperste leider moet ervoor zorg dragen, dat er tijdig, voldoende en op bekwame wijze aandacht aan deze vraagstukken wordt besteed. Hij zal zijn medewerkers hiertoe moeten kiezen, hij zal hen moeten stimuleren of afremmen, corrigeren of aanvullen. Maar het is goed dit uitdrukkelijk te stellen. $H_{i j}$ kan deze vraagstukken niet op zijn intuitie. alleen op basis van Fingerspitzengefühl oplossen. Grondige, wetenschappelijke analyse zal aan zijn beslissingen vooraf moeten gaan.

Opdat de hoofddirecteur zijn aandacht kan concentreren op deze constituerende toekomsttaak is het nodig dat hij voorzieningen treft, waardoor op bevredigende wijze in de dirigerende leiding van alle dag wordt voorzien. $E_{n}$ hierin is een belangrijke richtlijn gelegen, om een takkverdeling binnen het college van directeuren in al die gevallen, waar een meerhoofdige directie wordt aangetroffen, vast te stellen. Laten een aantal directeuren de taak voor wat betreft het leiding geven aan de dagelijkse bedrijfsvoering volledig voor hun rekening nemen, opdat één of meer directeuren hun aandacht volledig op de toekomst kunnen concentreren. Alleen dan kan worden voorkomen, dat de toekomst niet stiefmoederlijk wordt bedeeld.

Het is duidelijk, dat de doeltreffende organisatie van de opperste leiding voor het grootbedrijf een vraagstuk „op zich" wordt. Ten eerste het onderkennen van de facetten, waaraan regelmatig en systematisch aandacht moet worden geschonken. Ten tweede het formeren van een college van directeuren, waarin de gevarieerde deskundigheid, gegeven de aard van de vraagstukken, aanwezig is. Ten derde het zonder fricties tot stand brengen van de noodzakelijk geoordeelde taakverdeling en de hiermede samen-

5) Zie Prof. Dr. B. J. C. Lievegoed: De vorming van kader, in de reeks voordrachten op het gebied der interne organisatie voorjaar 1959 van het Nederlands Instituut van Accountants. 
hangende boven - en onderschikking. Ten vierde het kiezen van de medewerkers, zowel in de lijn als in de staf, die de directie bij haar vele taken terzijde dienen te staan. Ten vijfde het indoctrineren van het apparaat voor wat de filosifie van het bedrijf betreft, zoals deze door de opperste leiding wordt voorgestaan.

Het wekt de schijn, of deze analyse ons steeds verder van de stelling afdrijft, welke in dit artikel bewezen wil worden, namelijk dat het wel en wee ook van het grootbedrijf van één man afhangt. Want thans heeft onze analyse van de taak van de opperste leiding tot de conclusie geleid, dat deze taak veelomvattend en zeer verscheiden is. Dat één man deze taak, noch wat zijn beschikbare tijd, noch wat de verscheidenheid van deskundigheid betreft, kan omvatten; dat er dus behoefte is aan het inschakelen van vele mensen.

De besturende taak in het grootbedrijf vraagt dus een omvangrijk leidinggevend apparaat. De hoofddirecteur is een eenling in een grote mensenzee. $\mathrm{H}_{\mathrm{ij}}$ kan alleen niets. Hij behoeft de medewerking van vele, bekwame, toegewijde medewerkers. Die allen tezamen niet zelf doen, maar bevorderen dat gedaan wordt. Besturen, dat wil in laatste instantie naar mijn oordeel zeggen, bevorderen dat gedaan wordt. Er op toezien, dat gedaan wordt, dat wil zeggen de personen aanwijzen en de organen creëren, die deze besturende en toezichthoudende taak op onderdelen tot uitvoering brengen. De structuur scheppen, opdat de omvangrijke organisatie, de honderden of duizenden mensen, die in het grootbedrijf werkzaam zijn, veelal nog op geografisch gespreide plaatsen, een duidelijke taakstelling en taakaanwijzing hebben. Bestuurd worden door bekwame leiders, opdat de toezichthoudende personen en organen functioneren, die afwijkingen constateren, corrigeren en periodiek hierover naar boven rapporteren. En al deze leidinggevende organen behoeven op hun beurt ook weer leiding en toezicht. Deze besturende pyramide vindt tenslotte bij één of enkele mensen aan de top zijn eindpunt. En deze ene man aan de top beslist in laatste instantie over de beleidslijn, die gevolgd wordt op grond van zijn toekomst-visie. Hij heeft een beslissende invloed op de wijze, waarop zijn directe medewerkers zich van hun besturende en toezichthoudende taak kwijten. $Z_{i j}$ op hun beurt hebben weer een beslissende invloed naar beneden.

De gave van de hoofddirecteur om de mensen te kiezen, die in staat zijn op bevredigende wijze zijn visie in concrete aanwijzingen uit te werken, is voor het succes van zijn leiderschap bepalend. Uliteindelijk is leiding geven terug te brengen tot kiezen van mensen en indoctrineren van mensen met de eigen toekomst-visie. De bekwame leider weet de mensen die met hem samenwerken tot een topprestatie te brengen, een prestatie-niveau dat zij op eigen kracht, zonder deze leiding, niet zouden weten te bereiken. $Z_{i j}$ worden op beslissende momenten gestuurd, gecorrigeerd, over de hindernis heen geholpen, waardoor hun zelfvertrouwen groeit.

Maar indien de man aan de top wordt vervangen, breekt een critisch moment in het bestaan van het grootbedrijf aan. Blijkt de opvolger niet de juiste man te zijn, dan ontstaat er reeds spoedig verwarring. De zekerheid neemt af; dit gevoel van onzekerheid plant zich snel voort naar beneden. Er worden fouten gemaakt; er ontstaat discussie. De samenwerking gaat hokken; vrij spoedig is het fraaie en soepel functionerende bestuursapparaat ontregeld. Er worden onrechtvaardige beslissingen genomen. Er worden functionarissen overgeplaatst. Degenen, die proberen onjuiste aanwijzingen te corrigeren en dus de moed hebben van mening te verschillen, wordt te verstaan gegeven dat hun zelfstandigheid en initiatief niet op prijs wordt 
gesteld. De voorkeur van de opperste leiding gaat uit naar die medewerkers, die vlot en geruisloos overeenkomstig de aanwijzingen handelen. Evenzo voltrekt zich in het bedrijf, wat ik de wet van Gresham in de organisatieleer zou willen noemen. De wet van Gresham uit de sociale economie, meer speciaal de geldtheorie, luidt: bad money drives out good money. Analoog hiermede meen ik, dat voor de organisatie-leer de regel geldt: bad management drives out good people. Onbekwame leiding verdrijft bekwame mensen.

En tenslotte voltrekt zich langs deze weg de invloed van de hoofddirecteur in het grootbedrijf. Via het aantrekken of afstoten van bekwame medewerkers. Via de keuze, goede of slechte, van mensen. Via een stimulerende of een deprimerende invloed die van de man aan de top uitgaat. 